\title{
Surgical ventricular reconstruction with endocardectomy along radiofrequency ablation-induced markings
}

\author{
Vadim Babokin, MD, ${ }^{\mathrm{a}, \mathrm{b}}$ Vladimir Shipulin, MD, ${ }^{\mathrm{a}}$ Roman Batalov, MD, ${ }^{\mathrm{a}}$ and Sergey Popov, MD
}

\begin{abstract}
Objective: The objective of this study was to evaluate the efficacy of a novel approach for endocardectomy during coronary artery bypass graft with surgical ventricular restoration in patients with postinfarction left ventricular aneurysm.

Methods: One hundred sixty-eight patients underwent coronary artery bypass graft with surgical ventricular restoration from 2005 to 2011. Endocardectomy was performed as an integral part of surgical ventricular restoration for the prevention of ventricular tachycardia. The experimental group (surgical ventricular restoration-endocardectomy group; $\mathrm{n}=74$ ) underwent preoperative electrophysiologic study with electroanatomic left ventricular mapping. Radiofrequency ablation-induced markings were placed and were used later as guides for performing endocardectomy during coronary artery bypass graft with surgical ventricular restoration. The control group (surgical ventricular restoration group; $\mathrm{n}=94$ ) underwent surgical ventricular restoration without endocardectomy.
\end{abstract}

Results: The 1-year mortality rates in the surgical ventricular restoration-endocardectomy and surgical ventricular restoration (control) groups were 5\% and 13\%, respectively. During the postoperative period, 3\% of patients in the surgical ventricular restoration-endocardectomy group and $38 \%$ of patients in the surgical ventricular restoration group experienced ventricular tachycardia events $(P<.05)$. Automatic implantable cardioverter-defibrillators were implanted in 11 patients in the surgical ventricular restoration group and in 1 patient of the surgical ventricular restoration-endocardectomy group for secondary prevention of sudden cardiac death.

Conclusions: When performed as an integral part of surgical ventricular restoration, endocardectomy was crucial in preventing postoperative ventricular tachycardia. Use of radiofrequency ablation-induced markings allowed clear visualization of the reentry zones for efficient endocardectomy during coronary artery bypass graft with surgical ventricular restoration, resulting in better patient outcomes. (J Thorac Cardiovasc Surg 2013;146:1133-8)

Video clip is available online.

Development of postinfarction left ventricular aneurysm (LVA) significantly worsens the prognosis of coronary artery disease resulting from life-threatening complications. The 5-year survival rate in patients with untreated postinfarction aneurysms ranges between $25 \%$ and $60 \%$. Ventricular arrhythmia is the cause of mortality in $50 \%$ of patients with postinfarction left ventricular (LV) remodeling. ${ }^{1-3}$ The Multicenter Automatic Defibrillator Implantation Trial II

\footnotetext{
From the Institute of Cardiology, ${ }^{\mathrm{a}}$ Tomsk, Russia; and S.P. Botkin City Clinical Hospital, ${ }^{\mathrm{b}}$ Moscow, Russia.

Disclosures: Authors have nothing to disclose with regard to commercial support.

Received for publication April 24, 2012; revisions received Aug 14, 2012; accepted for publication Aug 24, 2012; available ahead of print Oct 15, 2012.

Address for reprints: Vadim Babokin, MD, Institute of Cardiology, Kievskaya St

111a, Tomsk, 634012, Russia (E-mail: veb@cardio.tsu.ru).

$0022-5223 / \$ 36.00$

Copyright (c) 2013 by The American Association for Thoracic Surgery

http://dx.doi.org/10.1016/j.jtcvs.2012.08.067
}

showed that implantation of an automatic implantable cardioverter-defibrillator (AICD) ${ }^{4}$ was life-saving for patients with severe LV dysfunction.

Surgery improves the prognosis and clinical course for patients with heart aneurysms. ${ }^{5-8}$ The Surgical Treatment for Ischemic Heart Failure Trial reported similar mortality rates in patients subjected to coronary artery bypass grafting $(\mathrm{CABG})$ with or without surgical ventricular reconstruction (SVR). ${ }^{9}$ These findings suggest the safety of an extra LV surgery, such as SVR, in addition to CABG in patients with coronary artery disease, LV dysfunction, and heart failure. The Surgical Treatment for Ischemic Heart Failure Trial investigators did not study associations between mortality and ventricular dysrhythmias. However, evidence suggests that a subendocardial scar burden may be a predictor of subsequent arrhythmogenicity. ${ }^{10}$ Many research teams have shown the efficacy of aneurysmectomy with endocardial resection in the treatment of ventricular tachycardia (VT). ${ }^{1-15}$

The objective of the study was to evaluate the clinical efficacy of a new approach for endocardectomy (EE) during $\mathrm{CABG} / \mathrm{SVR}$ in patients with postinfarction LVA. EE during 


\section{Abbreviations and Acronyms \\ AICD = automatic implantable cardioverter- defibrillator \\ $\mathrm{CABG}=$ coronary artery bypass grafting \\ $\mathrm{EE}=$ endocardectomy \\ EPS = electrophysiologic study \\ $\mathrm{LV}=$ left ventricular \\ LVA $=$ left ventricular aneurysm \\ RFA-M = radiofrequency ablation-induced marking \\ SVR = surgical ventricular reconstruction \\ VT $=$ ventricular tachycardia}

SVR was guided by radiofrequency ablation-induced markings (RFA-Ms), placed during a preoperative intracardiac electrophysiologic study (EPS) with electroanatomic mapping of the left ventricle.

\section{METHODS}

From January 2005 to December 2011, 5091 cardiopulmonary bypass surgeries were performed at the authors' institute, including 2318 surgeries for coronary artery disease. Of these, 264 of the operated patients had ischemic cardiomyopathy and LVA. Patients with postinfarction anteroseptal LVA with LV remodeling types I, II, and $\mathrm{III}^{16}$ were included in the study $(n=168)$. Patients with posterior LVA were excluded from the study. Preoperatively, most patients enrolled in the study were diagnosed with angina of Canadian Cardiovascular Society class III or IV and heart failure of New York Heart Association class II or III (Table 1). According to ventriculography and echocardiography, all patients had signs of postinfarction LV remodeling.

From May 2007, EPS with electroanatomic mapping of the left ventricle $^{17}$ was included in the preoperative examination of patients for identification of delayed conduction areas, reentry zones, and VT inducibility (Figure 1, Video 1). The identified arrhythmogenic zones were marked with RFA-Ms by using an ablation electrode with a radiofrequency power of $45 \mathrm{~W}$ and saline irrigation at $17 \mathrm{~mL} / \mathrm{min}$. The RFA-Ms were placed on the borders of pathologic zones for their further resection during open surgery and remained visible for up to 10 days after application. The exclusion criteria for performing EPS were thrombus in the LV cavity; aortic, iliac, and femoral arterial occlusion and stenosis; and refusal by the patient to participate in the study.

The SVR procedures were performed using the standard methods developed by Dor and colleagues ${ }^{6}$ or Menicanti and associates ${ }^{8}$ with or without EE. ${ }^{11-15}$ One hundred thirty patients underwent aneurysm resection and LV reconstruction using the method by Dor and colleagues, ${ }^{6}$ whereas 38 patients underwent SVR as done by Menicanti and associates. ${ }^{8}$ Repair of mitral valve insufficiency with a mitral annuloplasty ring was performed in 26 patients from both groups. All 168 patients underwent CABG surgery.

All 168 patients were allocated retrospectively to 2 groups. The main group $(\mathrm{n}=74)$ included patients subjected to SVR with EE $(\mathrm{SVR} / \mathrm{EE}$ group). The control group consisted of 94 patients who underwent SVR without endocardial resection (SVR group). Preoperative cardiac magnetic resonance imaging of the diastolic phase in a synchronizing mode showed infarcted myocardium perimeters of $55.5 \% \pm 5.3 \%$ and $49.8 \% \pm 6.7 \%$ of the total LV perimeter in the SVR/EE and control SVR group, respectively. According to preoperative Holter monitoring, $43 \%$ of the patients undergoing SVR/EE and $49 \%$ of the control SVR patients had ventricular extra systoles. Data from the clinical and instrumental examinations did not reveal significant differences between the groups before treatment.
Not all patients from the main and control groups underwent both preoperative and postoperative EPS procedures with LV electroanatomic mapping. Some patients had contradictions, whereas others refused to undergo EPS examination. Patients from the SVR/EE and control SVR groups who underwent both preoperative and postoperative EPS were assigned retrospectively to subgroups A $(\mathrm{n}=38)$ and $\mathrm{B}(\mathrm{n}=32)$, respectively.

Four surgeons operated on patients from the control SVR group starting in January 2005. In May 2007, 2 of the 4 surgeons, after being trained in the EE procedure, started to perform SVR/EE $(n=74)$. No significant differences in the outcomes of the CABG/SVR procedures were found in patients operated on by different surgeons. The EE technique consists of isolating and resecting the septal, apical, and anterior LV walls and endocardial scar tissue according to RFA-Ms applied to the scarred area 4 to $5 \mathrm{~mm}$ from the border between the scar and vital myocardium. The average area of resected endocardium was $48 \mathrm{~cm}^{2}$ (range, $18-83 \mathrm{~cm}^{2}$ ).

The postoperative antithrombotic protocol in uncomplicated patients did not differ between the groups and included low-molecular weight heparin for 3 days after the operation, acetylsalicylic acid $75 \mathrm{mg} /$ day, and/or clopidogrel $75 \mathrm{mg} /$ day. Patients with atrial fibrillation and/or mitral valve repair received warfarin therapy with anticoagulation control (international normalized ratio, 2.0-3.0).

Statistical analyses were done with SSPS 11.5 for Windows. Distributions of the quantitative variables were evaluated for normality by the Shapiro-Wilk test. Normally distributed data were described with the mean and standard deviation. Qualitative data were described with the occurrence rate or percentage. To evaluate the significance of differences between quantitative values in the compared groups, Student $t$ test was applied after confirmation of normal distribution. The $\mathrm{Z}$ criterion (Fisher exact test) was used to determine whether there were nonrandom associations between the categorical variables. The significance of differences in postoperative mortality was evaluated using the Kaplan-Meier method. Values were considered statistically significant when $P$ was $<.05$. The study was approved by the local ethics committee of the authors' institute.

\section{RESULTS \\ Survival}

The overall in-hospital mortality for patients who underwent SVR was $4 \%$ (7/168 patients). The mortality rates were $1 \%(1 / 74$ patients) for the SVR/EE group and $6 \%$ (6/94 patients) for the control SVR group. One patient from the SVR/EE group died from low cardiac output syndrome on postoperative day 12. In the control group, 3 patients were diagnosed with perioperative myocardial infarction and progressive heart failure, 2 died from low cardiac output syndrome, and 1 patient died from stroke.

One-year survival rates were $95 \%$ (70/74 patients) in the SVR/EE group and $87 \%$ (82/94 patients) in the control SVR group $(P<.05)$. Causes of postoperative mortality in the SVR/EE group were progressive heart failure, acute myocardial infarction, and noncardiac reason (1 patient). Causes for postoperative mortality in the control group were progressive heart failure (2 patients), stroke (1 patient), and sudden cardiac death resulting from to VT or ventricular fibrillation (3 patients).

\section{Cardiac Function}

Progressive improvement in LV function was confirmed by echocardiography 1 month after surgery. The LV 
TABLE 1. Preoperative clinical characteristics of the patients

\begin{tabular}{|c|c|c|}
\hline Patient characteristics* & $\begin{array}{c}\text { SVR/EE } \\
\text { (main group, } \\
n=74)\end{array}$ & $\begin{array}{c}\text { SVR } \\
\text { (control group, } \\
\mathbf{n}=94)\end{array}$ \\
\hline Median age, y (interquartile range) & $54(50-60)$ & $56(52-62)$ \\
\hline Female sex, n (\%) & $6(8)$ & $7(7)$ \\
\hline No. of previous MIs, mean \pm SD & $1.4 \pm 0.5$ & $1.3 \pm 0.5$ \\
\hline Time from previous MI, y, mean \pm SD & $3.7 \pm 0.9$ & $3.9 \pm 1.2$ \\
\hline \multicolumn{3}{|l|}{ Current CCS angina class, $\mathrm{n}(\%)$} \\
\hline Class II & $7(9)$ & $9(10)$ \\
\hline Class III & $27(36)$ & $34(36)$ \\
\hline Class IV & $26(35)$ & $34(36)$ \\
\hline Unstable angina & $14(19)$ & $17(18)$ \\
\hline \multicolumn{3}{|l|}{ Current NYHA heart failure class, n (\%) } \\
\hline Class I & $1(1)$ & $3(3)$ \\
\hline Class II & $15(20)$ & $21(22)$ \\
\hline Class III & $52(70)$ & $65(69)$ \\
\hline Class IV & $6(8)$ & $5(5)$ \\
\hline \multicolumn{3}{|l|}{ Type of LVA, n (\%) } \\
\hline 1 & $41(55)$ & $55(58)$ \\
\hline 2 & $26(35)$ & $32(34)$ \\
\hline 3 & $7(9)$ & $7(7)$ \\
\hline \multicolumn{3}{|l|}{ Ventricular tachycardia, n (\%) } \\
\hline Spontaneous & $11(15)$ & $12(13)$ \\
\hline Induced & $26(35)$ & $28(30)$ \\
\hline Ventricular extrasystoles, n (\%) & $32(43)$ & $46(49)$ \\
\hline $\begin{array}{l}\text { Mitral regurgitation } 2+\text {, fibrous } \\
\quad \text { ring }>35 \mathrm{~mm}, \mathrm{n}(\%)\end{array}$ & $13(18)$ & $13(14)$ \\
\hline \multicolumn{3}{|l|}{ Coronary artery lesions, n ( $\%)$} \\
\hline 1 & $24(32)$ & $33(35)$ \\
\hline 2 & $25(34)$ & $33(35)$ \\
\hline 3 & $25(34)$ & $28(30)$ \\
\hline Diabetes mellitus, n (\%) & $19(26)$ & $23(24)$ \\
\hline Hypertension, n (\%) & $47(64)$ & $63(67)$ \\
\hline
\end{tabular}

Values are mean \pm standard deviation. $S V R$, Surgical ventricular reconstruction; $E E$, endocardectomy; $M I$, myocardial infarction; $S D$, standard deviation; $C C S$, Canadian Cardiovascular Society; NYHA, New York Heart Association; LVA, left ventricular aneurysm. $* P>.05$ for all between-group comparisons.

ejection fraction increased from $39 \%$ before surgery to $48 \%$ after surgery $(P<.01)$ in the SVR/EE group and from $40 \%$ to $51 \%(P<.01)$ in the control SVR group. The mean LV end-diastolic volume index decreased from $116 \mathrm{~mL} / \mathrm{m}^{2}$ to $80 \mathrm{~mL} / \mathrm{m}^{2}(P<.01)$ in the $\mathrm{SVR} / \mathrm{EE}$ group and from $111 \mathrm{~mL} / \mathrm{m}^{2}$ to $79 \mathrm{~mL} / \mathrm{m}^{2}(P<.01)$ in the control group. The LV end-systolic volume index decreased from $74 \mathrm{~mL} / \mathrm{m}^{2}$ to $49 \mathrm{~mL} / \mathrm{m}^{2}(P<.01)$ and from $68 \mathrm{~mL} / \mathrm{m}^{2}$ to $47 \mathrm{~mL} / \mathrm{m}^{2}(P<.01)$ in the SVR/EE and control groups, respectively. No statistically significant differences were found between the hemodynamic values in the groups.

\section{EPS With LV Electroanatomic Mapping}

As mentioned, patients from the SVR/EE and control SVR groups who underwent both preoperative and postoperative EPS with LVelectroanatomic mapping were divided into subgroups $A(n=38)$ and $B(n=32)$, respectively. We found

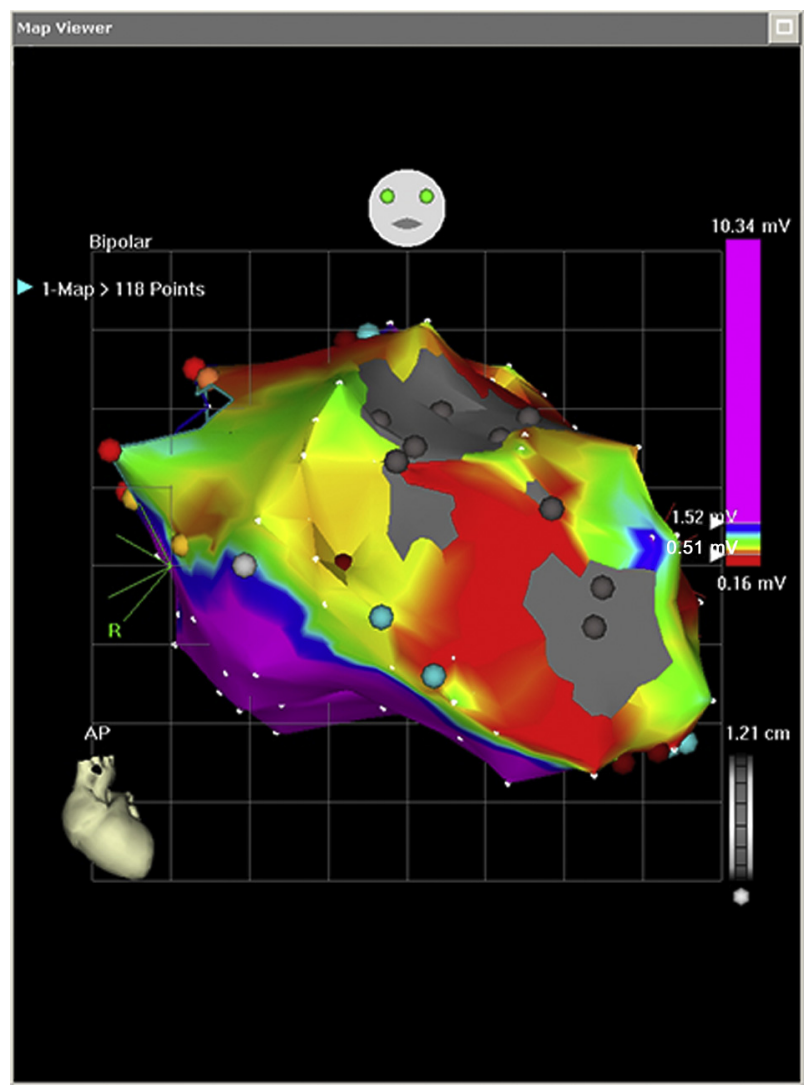

FIGURE 1. Preoperative electrophysiologic study and electroanatomic left ventricular mapping showing the zones of electrical silence (scar tissue; gray), zones of low-amplitude ventricular capacity of about $0.5 \mathrm{mV}$ (red), transient zones from 0.5 to $1.5 \mathrm{mV}$ (yellow-green-blue), vital myocardium zones (violet), double capacity (blue dots), delayed conduction zones (pink dots), radiofrequency ablation-induced markings on the borders between pathologic zones and vital myocardium (maroon dots). $R$, Right side; $A P$, anterior-posterior projection (anterior view).

improvement in the EPS parameters after SVR/EE in all patients of subgroup A. Electrical scar zones were identified only in the areas of endoventricular patches, low-conduction areas disappeared completely, and transient zones (0.5-1.5 $\mathrm{mV}$ ) comprised a limited area with unlikely reentry occurrence and VT induction (Figure 2, Video 2). In subgroup A, monomorphic VT was induced in only 1 patient, who had incomplete endocardectomy (Table 2). No spontaneous VT episodes occurred in this subgroup postoperatively.

According to Holter monitoring data, spontaneous VT episodes were documented in 5 patients in subgroup B, and VT was induced during EPS in 7 patients in this subgroup within the first postoperative year (Figure 3, Video $3)$. Spontaneous and induced VT events affected $38 \%$ of patients (12/32) from subgroup B.

For secondary prevention of sudden cardiac death, AICDs were implanted in 11 patients $(34 \%)$ of subgroup $\mathrm{B}$ and 1 patient $(3 \%)$ of subgroup A (Table 3 ). 


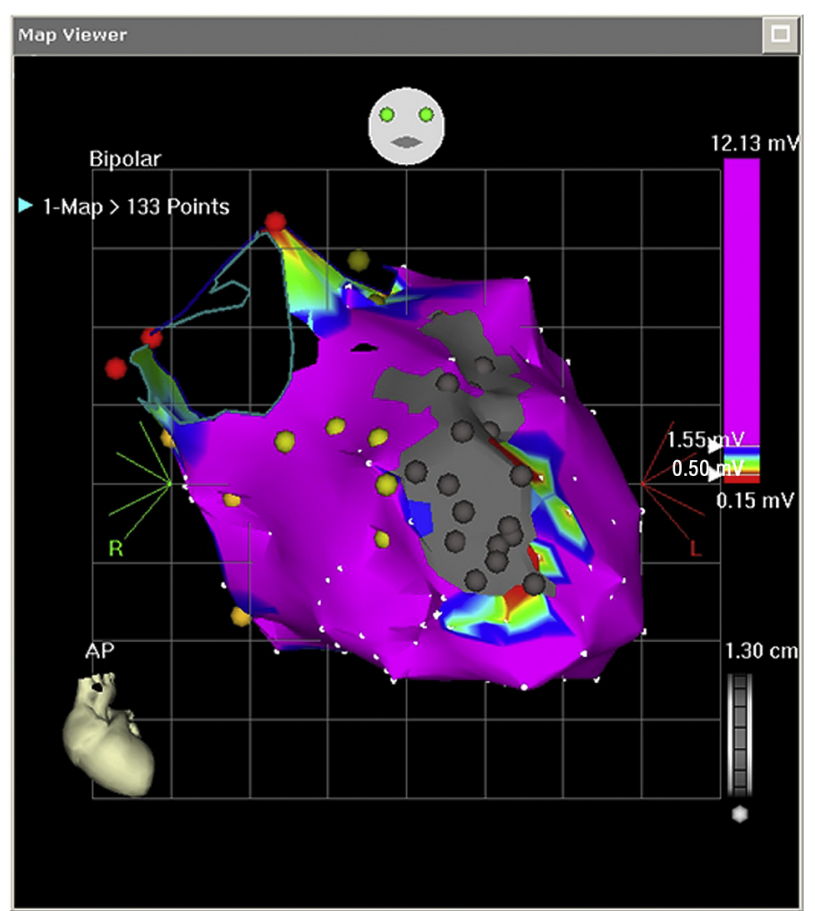

FIGURE 2. Electrophysiologic study and electroanatomic left ventricular mapping after surgical ventricular reconstruction with endocardectomy (40 $\mathrm{cm}^{2}$ ) of the entire apex, half of the ventricular septum, and the anterior left ventricular wall. Electrical scar was found in an area of the endoventricular patch only (gray). The transient zone (yellow-green-blue) was found in a limited area with an unlikely occurrence of reentry and ventricular tachycardia induction. Yellow dots show His bundle and left bundle branch. $R$, Right side; $A P$, anterior-posterior projection (anterior view).

\section{DISCUSSION}

Infarcted LV myocardium may cause fatal ventricular arrhythmias. $^{1-4,18}$ Recent studies have shown that the myocardial zone surrounding LVA scar tissue is a source of monomorphic and polymorphic premature ventricular contractions. ${ }^{19}$ The larger the postinfarction area according to magnetic resonance imaging, the greater the risk of developing VT. ${ }^{10}$ Endocardial mapping provides valuable information on the presence and localization of LV excitation sites and facilitates further surgical treatment. ${ }^{3,6,18}$

The transient zone between scar tissue and vital myocardium, with potentials ranging from 0.5 to $1.5 \mathrm{mV}$, is

TABLE 2. Ventricular tachycardia in patients before and after surgery

\begin{tabular}{|c|c|c|c|c|}
\hline \multirow[b]{2}{*}{ Variable } & \multicolumn{2}{|c|}{$\begin{array}{c}\text { SVR/EE } \\
(\text { subgroup } \mathbf{A}, \mathbf{n}=38)\end{array}$} & \multicolumn{2}{|c|}{$\begin{array}{c}\text { SVR } \\
(\text { subgroup } \mathbf{B}, \mathbf{n}=32)\end{array}$} \\
\hline & Spontaneous & Induced & Spontaneous & Induced \\
\hline Before surgery, $\mathrm{n}(\%)$ & $6(16)$ & $15(39)$ & $6(19)$ & $12(38)$ \\
\hline After surgery, n (\%) & $0 *$ & $1(3)^{*}$ & $5(16) \dagger$ & $7(22) \dagger$ \\
\hline
\end{tabular}

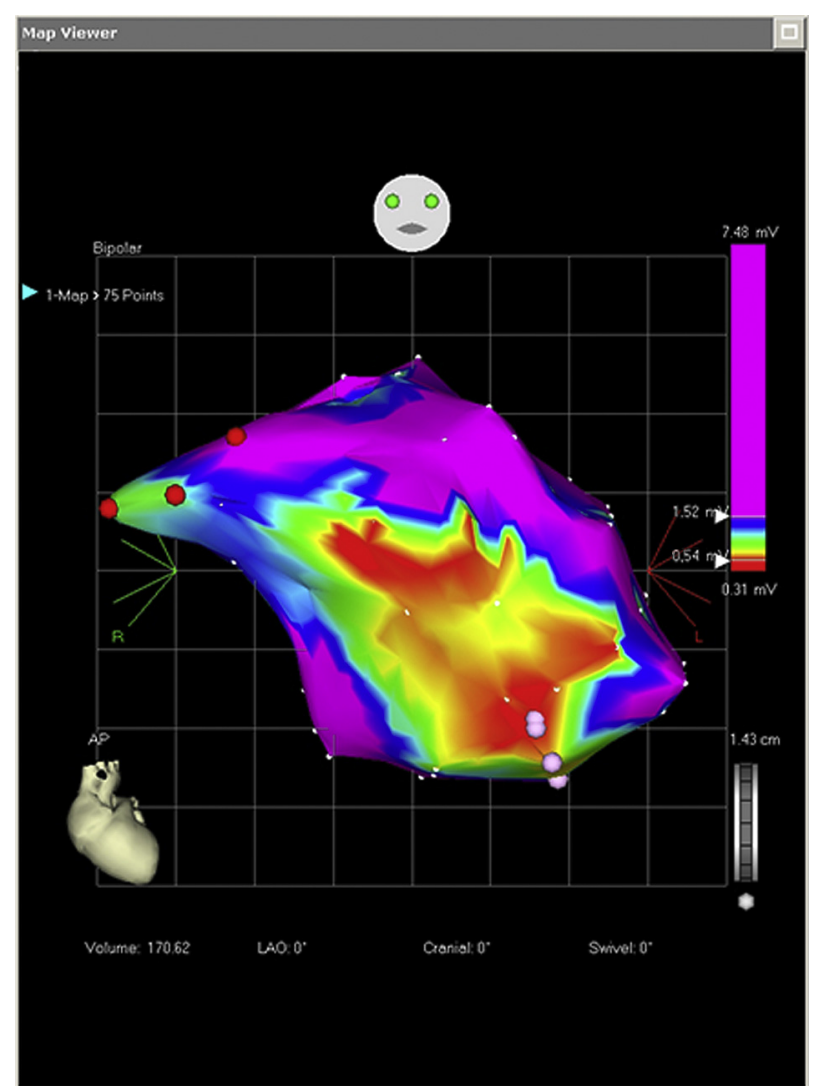

FIGURE 3. Electrophysiologic study and electroanatomic left ventricular mapping after surgical ventricular reconstruction without endocardectomy; coronary artery bypass graft surgery was performed. Noted are large zones of low-amplitude ventricular capacity (red) and transient zones (yellow-greenblue) with delayed conduction zones (pink dots). Ventricular tachycardia was registered during the postoperative period. A cardioverter-defibrillator was implanted in this patient. $R$, Right side; $A P$, anterior-posterior projection (anterior view); $L A O$, left anterior oblique view.

of special interest. Both double potential and delayed conduction are usually found in this zone, and this potential may cause reentry and VT. We used RFA to mark

TABLE 3. Outcomes and subsequent procedures

SVR/EE

SVR

(subgroup A, (subgroup B,

Variable, $\mathbf{n}(\%)$

$\mathbf{n}=\mathbf{3 8}$ )

$\mathbf{n}=\mathbf{3 2}$ )

Outcome

Acute myocardial infarction

Stroke

$1(3)$

2 (6)

Low cardiac output syndrome

0

$2(6)$

Renal failure

2 (6)

$2(6)$

Death from any cause within 1 year

$1(3)$

1 (3)

0

after surgery

Subsequent procedure

Coronary artery bypass graft

1 (3)

1 (3)

0

AICD placement

$11(34)^{*}$

$S V R$, Surgical ventricular reconstruction; $E E$, endocardectomy; $A I C D$, automatic implantable cardioverter-defibrillator. ${ }^{*} P<.05$ between groups. 
pathologic zones found during EPS. The RFA-Ms appeared as yellow-brown spots with clear edges and a size of about 4 to $5 \mathrm{~mm}$. According to intraoperative data, the RFA-Ms remained visible for approximately 10 days after application. Clear visualization of the affected endocardium, including transient zones with reentry sources, enabled optimal resection of the endocardium within the verified edges.

Although not all surgeons perform SVR to treat LV systolic dysfunction, ${ }^{9}$ SVR with EE may prevent the development of fatal ventricular rhythm disturbances. ${ }^{11,13,15}$ Known surgical approaches in the treatment of patients with postinfarction LVA include partial isolation of affected endocardial areas from the LV cavity, often without their complete resection, which leaves VT sources in the heart and may necessitate further AICD implantation. ${ }^{9,12}$ The use of RFA-Ms during EPS guided the endocardial resection process, allowing us to remove only the abnormal tissue without altering the vital tissue. This process prevented complications, such as low cardiac output resulting from excessive myocardial resection and VT resulting from to insufficient EE. The single postoperative case of VT induction in a patient with incomplete resection of abnormal endocardium (subgroup A) demonstrated the importance of performing the EE procedure correctly. To our knowledge, no available study in the literature describes identical or similar approaches to VT treatment in patients with postinfarction changes in the heart.

The results of postoperative EPS with electroanatomic LV mapping in the SVR group without EE showed that the sources of reentry and VT found preoperatively persisted after SVR, which posed a high patient health risk (Figure 3, Video 3). Twelve patients (38\%) in the SVR group without EE had indications for AICD placement as a secondary prevention of sudden cardiac death after surgery (Table 2; ie, VT episodes were registered postoperatively). However, most patients who underwent SVR/EE did not have such indications. No significant differences were observed in the rates of postoperative complications between the groups, and no strokes were observed in subgroup A (Table 3). These results suggest that SVR/EE did not increase the risks compared with SVR without EE. The observed low mortality rate and very low rate of indications for AICD placement confirmed the superiority of SVR/EE over SVR without EE.

\section{Limitations}

We did not perform both preoperative and postoperative EPS in some patients because of contraindications, technical reasons, or refusal by the patient to undergo the examination. Although this study represents a large EPS series in patients with postinfarction LVA, the data acquired during the 5-year postoperative follow-up period have not yet been analyzed. Decisions regarding the preferred surgical approach (SVR/EE or SVR alone) for patients were made by our 4 surgeons according to their preference. Despite the comparable number of different aneurysm types in the main and control groups, we did not compare the subgroups with the same LVA types.

\section{CONCLUSIONS}

Our data suggest that endocardial resection of scarred and transient LV areas is a crucial aspect in the surgical treatment of postinfarction heart aneurysms because it prevents postoperative VT episodes. Endocardial EPS and electroanatomic LV mapping allow the identification of zones with likely reentry occurrence. When placed during endocardial EPS, RFA-Ms may aid in the precise identification of the area of a lesion during open surgery for the optimal performance of EE.

\section{References}

1. Di Donato M, Sabatier M, Dor V, Buckberg G, the RESTORE Group. Ventricular arrhythmias after LV remodeling: surgical ventricular restoration or ICD? Heart Fail Rev. 2005;9:299-306.

2. Sosa E, Jatene A, Kaeriyama JV, Scanavacca M, Marcial MB, Bellotti G, et al. Recurrent ventricular tachycardia associated with postinfarction aneurysm: results of left ventricular reconstruction. J Thorac Cardiovasc Surg. 1992;103. 855-60.

3. Dor V, Sabatier M, Montiglio F, Rossi P, Toso A, Di Donato M. Results of nonguided subtotal endocardiectomy associated with left ventricular reconstruction in patients with ischemic ventricular arrhythmias. J Thorac Cardiovasc Surg. 1994;107:1301-8.

4. Moss AJ, Zareba W, Hall WJ. Prophylactic implantation of a defibrillator in patients with myocardial infraction and reduced ejection fraction. $N$ Engl J Med. 2002;346:877-83.

5. Braunwald E, Pfeffer MA. Ventricular enlargement and remodeling following acute myocardial infarction: mechanisms and management. Am J Cardiol. 1991;68:1-6.

6. Dor V, Sabatier M, Montiglio F, Rossi P, Toso A, Di Donato M. Endoventricular patch reconstruction of ischemic failing ventricle: a single center with 20 years experience. Heart Fail Rev. 2004;9:269-86.

7. Faxon DP, Myers WO, McCabe CH, Davis KB, Schaff HV, Wilson JW, et al. The influence of surgery on the natural history of angiographically documented left ventricular aneurysm: the Coronary Artery Surgery Study. Circulation. 1986; 74:110-8.

8. Menicanti L, Castelvecchio S, Ranucci M, Frigiola A, Santambrogio C, de Vincentiis C, et al. Surgical therapy for ischemic heart failure: single-center experience with surgical anterior ventricular restoration. J Thorac Cardiovasc Surg. 2007;134:433-41.

9. Jones RH, Velazquez EJ, Michler RE, Sopko G, Oh JK, O'Connor CM, et al. Coronary bypass surgery with or without surgical ventricular reconstruction. $N$ Engl J Med. 2009;360:1705-17.

10. Crawford T, Cowger J, Desjardins B, Kim HM, Good E, Jongnarangsin K, et al. Determinants of postinfarction ventricular tachycardia. Circ Arrhythm Electrophysiol. 2010;3:624-31.

11. Josephson ME, Harken AH, Horowitz LN. Endocardial excision: a new surgical technique for the treatment of recurrent ventricular tachycardia. Circulation 1979;60:1430-9.

12. Harken AH, Horowitz LN, Josephson MD. Comparison of standard aneurysmectomy and aneurysmectomy with directed endocardial resection for the treatment of recurrent sustained ventricular tachycardia. J Thorac Cardiovasc Surg. 1980; 80:527-34.

13. Horowitz LN, Harken AH, Kastor JA, Josephson ME. Ventricular resection guided by epicardial and endocardial mapping for treatment of recurrent ventricular tachycardia. N Engl J Med. 1980;302:589-93.

14. Ostermeyer J, Borggrefe M, Brethardt G, Podczek A, Goldmann A, Schoenen JD. Direct operations for the management of life-threatening ischemic ventricular tachycardia. J Thorac Cardiovasc Surg. 1987;94:848-61. 
15. Dor V, Sabatier M, Di Donato M, Maioli M, Toso A, Montiglio F. Late hemodynamic results after left ventricular patch repair associated with coronary grafting in patients with postinfarction akinetic or dyskinetic aneurysm of the left ventricle. J Thorac Cardiovasc Surg. 1995;110: 1291-301

16. Di Donato M, Castelvecchio S, Kukulski T, Bassadori C, Giacomazzi F, Frigiola A, et al. Surgical ventricular restoration: left ventricular shape influence on cardiac function: clinical status and survival. Ann Thorac Surg. 2009;87: 455-61.
17. Kautzner J. Clinical application of electro-anatomical mapping in the treatment of arrhythmias. In: Kautzner J, Kirstein Pedersen A, Peichl P, eds. Electroanatomical mapping of the heart. London, England: Remedica Publishing; 2006. 3.8-3.14.

18. Moran JM. Postoperative ventricular arrhythmia. Ann Thorac Surg. 1984;38: 312-3.

19. Marrouch NF, Verna A, Wazni O, Schweikert R, Martin DO, Saliba W, et al. Mode of initiation end ablation of ventricular fibrillation storms in patients with ischemic cardiomyopathy. J Am Coll Cardiol. 2004;43:1715-20.

Access to The Journal of Thoracic and Cardiovascular Surgery Online is reserved for print subscribers!

Full-text access to The Journal of Thoracic and Cardiovascular Surgery Online is available for all print subscribers. To activate your individual online subscription, please visit The Journal of Thoracic and Cardiovascular Surgery Online, point your browser to http://www.mosby.com/itcvs, follow the prompts to activate your online access, and follow the instructions. To activate your account, you will need your subscriber account number, which you can find on your mailing label (note: the number of digits in your subscriber account number varies from 6 to 10). See the example below in which the subscriber account number has been circled:

\section{Sample mailing label}

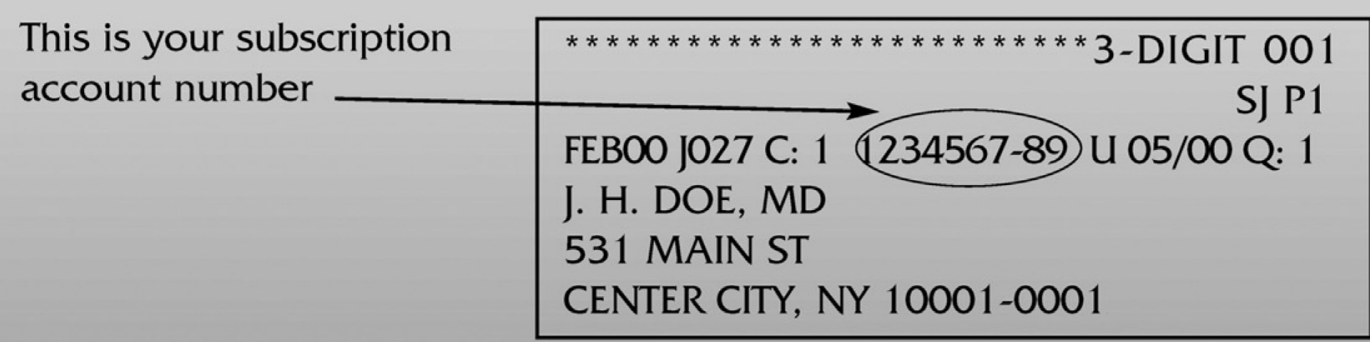

Personal subscriptions to The Journal of Thoracic and Cardiovascular Surgery Online are for individual use only and may not be transferred. Use of The Journal of Thoracic and Cardiovascular Surgery Online is subject to agreement to the terms and conditions as indicated online. 